\title{
Formation of Professional-Mathematical Competence of Students in the Field of Technical Training Based on Interdisciplinary Integration of Mathematics and Computer Science
}

Lidya N. Vasileva

Tatyana V. Kartuzova

Anatoliy V. Merlin

Nadezhda I. Merlina

Chuvash State University, Cheboksary, Russia

Email: OLN2404@mail.ru

Natalya I. Svetlova

Moscow Humanitarian-Economic Institute, Chuvash Branch, Cheboksary, Russia

Doi:10.5901/mjss.2015.v6n2s3p90

\section{Abstract}

The urgency of the problem under investigation is determined by the growing demand in the competent graduates in the field of technical training, who are ready to solve professional problems based on fundamental mathematical knowledge and practical skills, carrying out mathematical modeling of the studied processes and phenomena using mathematical application software packages. The article aims to study the theoretical and practical implementation of the methodic of the professionalmathematical competence forming of students in the field of technical training based on the integration of mathematics and computer science. The major approaches to the study of this problem are competence, integrative and activity to learning which let to identify trends in the development of professional qualities of the student's personality through the integration of various activities by the decision of professionally-oriented tasks, taking into account individual characteristics and needs of the personality at every stage of vocational education. The formation of the professional-mathematical competence of students in the field of technical training through the integration of mathematics and computer science is considered as a target and as a learning process. Its backbone core in the forming structure of professionally-mathematical competence of students in the field of technical training stands out the mathematical modeling. The didactic object of the integration is the exploration and decision of professionally oriented integrative tasks. The materials of the article may be useful for university teachers who give lessons on professional-mathematics courses for students in the field of technical training.

Keywords: professional and mathematical competence; integration; professionally oriented task integration of character.

\section{Introduction}

\subsection{Background}

Social and economic transformations of modern society have influenced the change of technical students training goals. In the condition of a market economy and the need to use high-end technologies in the production the bachelors are now in demand, those who have a fundamental mathematical knowledge, able to use appropriate mathematical apparatus, to develop new and optimize existing solutions, to surf freely the information space, possessing relevant information and ability to its continuous update. The priority component of students' vocational training is the mathematical training, which contributes to a professional-mathematical competence of a technical graduate.

The main provisions of the competence approach to education are consistent with the idea of mathematics and computer science integration in the professional-mathematical activity of future bachelors. The work with modern mathematical software packages and information and communication technologies forms the students' ability to formulate and solve problems using the computer, its application as a tool of knowledge, organization of search and research activities, reveals the new potential for academic interaction of students and teachers, enables each student to realize 
his/her intellectual potential to the greatest extent.

\subsection{Explore Importance of the Problem}

The feature of a new look at solving the problem of technical training of future bachelors in terms of education informatization is to find approaches to professional and personal development of students and the determination of the content, methods and forms of education. Formation of fundamental mathematical knowledge and skills, as well as their use provision in a continuously developing information tools are one of the conditions for the preparation of highly qualified graduates. Here can play an important role the methods of computer science, which should appear as a tool for the implementation of the integrative links of professionally oriented mathematical activity.

\subsection{Integration of Mathematics and Computer Science}

The main provisions of the competence approach to education consistent with the idea of mathematics and computer science integration in the professional-mathematical activity of students.

A considerable amount of works is devoted to the study of the mathematics and computer science integration process. In the dissertation of I.N. Polunina (2003) 'the integration of mathematics and computer science courses' acts as an optimization factor of general professional training in the secondary vocational school; 'integrated lessons and their series' become the subject of G.L. Lukankin (2000) and A.N. Pavlov (2002) studies; 'systems of computer mathematics as a means of achieving a high level of integration of physics and mathematics in the personalized education' is considered by V.V. Solonin (2004).

The work with modern mathematical software packages and information and communication technologies forms the students ability to set and solve problems using the computer, its application as a tool of knowledge, organization of search and research activities, reveals new potential for academic interaction of students and teachers, gives each student an opportunity to realize their intellectual potential (Merlin, 2006).

Integrative links between mathematics and computer science are based on the data content of the subject areas. In the process of learning mathematics a logical and algorithmic training of students is forming, skills of building mathematical models of phenomena and processes and for fulfilling numeric evaluation are developing, etc. Computer Science training provides the basis for understanding the information nature of the studied phenomena, allows the formulation and solution of problems in an effective visual form.

\subsection{Status of the Problem}

Various aspects of definition and formation of the professional - mathematical competence of students of engineering universities have been considered in such dissertations as: G.I. Illarinova (2008), M.M. Minshin (2011), O.A. Valikhanova (2008). Theoretical and methodological aspects of the integration processes in education are analyzed in the works of V.I. Bezrukova (1990), U.N. Kulyutkin (1981), G.F. Fedoretc (1989). Problems of interdisciplinary links in training are considered in researches: G.I. Belenky (1985), V.A. Dalinger (2001), L.V. Zankov (1990) and others. However, methodical aspects of improving of mathematical training of students in the field of technical training, based on the integration of mathematics and computer science and promoting the professional and mathematical competence, are underrepresented in these studies.

\subsection{Hypothesis of the research}

Analysis of theoretical studies and practical activities in the aspect of the developed problem has showed that issues related to professional-mathematical training of students in the field of technical training is the understudied area of scientific knowledge and practical activities that enabled us to formulate hypotheses of the research of this problem: the formation of the professional-mathematical competence of students will be more effective if the learning process of future bachelors is realized through the integration of mathematics and computer science. 


\section{Materials and Methods}

\subsection{Objectives of the research.}

In the process of study the following objectives have been decided : 1) to specify the nature and structure of the concept "professional-mathematical competence of students in the field of technical training"; 2) to identify opportunities for integration of mathematics and computer science in the formation system of professional-mathematical competence of students in the field of technical training; 3 ) to develop, justify theoretically and disclose the formation methodic of the professional-mathematical competence of students in the field of technical training based on the integration of mathematics and computer science; 4) experimentally verify the effectiveness of forming the professional-mathematical competence of students in the field of technical training methodic through the integration of mathematics and computer science.

\subsection{Theoretical and empirical methods.}

To verify the hypothesis it has been used a complex of variety methods, complementing each other:

- theoretical (analysis of scientific and pedagogical literature, teaching experience, abstraction, modeling, synthesis and interpretation of the research results);

- empirical (research of the advanced experience, educational and methodical documentation, pedagogical observation, interviews, questionnaires and testing of students and teachers, pedagogical methodic, pedagogical experiment).

\subsection{The base of the research:}

Federal State Budgetary Educational Institution of Higher Professional Education "Chuvash State University named after I.N. Ulyanov".

\subsection{Stages of the research}

At the first stage, it has been studied and analyzed scientific, educational and methodical literature to clarify the state of the research problem, have been defined the initial parameters of the research, has been specified interpretation of the concept "professional-mathematical competence of students in the field of technical training", has been planned and conducted the ascertaining experiment.

At the second stage, there have been identified and justified the main components of the professionalmathematical competence of students in the field of technical training; has been developed a methodic of the competence formation based on the integration of mathematics and computer science; has been considered the content design of training that contribute to the professional - mathematical competence formation of students in the field of technical training; a searching experiment has been carried out.

At the third stage, it has been carried out the formating experiment in order to verify the developed methodic of professionally-mathematical competence formation of students in the field of technical training based on the integration of mathematics and computer science, has beenperformed the statistical analysis of the experimental data, conclusions have been done.

\subsection{Meaning and content of the concept "professional-mathematical competence of students in the field of technical} training"

The professional-mathematical competence of students in the field of technical training is considered by us as an integral characteristic that determines the ability and willingness of future bachelors to solve problems arising in the field of engineering activities, based on the fundamental mathematical knowledge, practical skills and abilities to carry out mathematical modeling of the studied processes and phenomena with the help of mathematical software packages and information and communication technologies (Vasiliev, 2013).

The professional-mathematical competence of students in the field of technical training is a complex entity comprising several components.

Considering the specificity of future bachelors' technical training and basing on the requirements of the Federal 
State Educational Standards of Higher Vocational Education, we believe that the structure of the professional mathematical competence is a combination of the following elements:

- the motivational component characterizes the presence of values, motives and interests, aimed at professional - mathematical training;

- the cognitive component determines the presence of theoretical and practical knowledge generated in the course of professional - mathematical education and self-education, which provide students with the ability to perform mathematical modeling of studies with the help of mathematical software packages;

- the activity component comprises a set of actions for self-regulation and the ability to make decisions, the elements of professional creativity and self-esteem;

- the reflexive component allows you to solve the problem consciously, to evaluate the process and the result of their own learning and the reproduction of the experience gained in the result of training.

2.6 Features of the mathematics and computer science integration in the structure of professional-mathematical competence formation of students in the field of technical training

The integration of knowledge in the process of professional - mathematical training of future bachelors in the field of technical training is understood by us, at first, as the creation of the students' holistic view about the world and its future profession and, secondly, as the process leading to the goal achievement, during which qualitatively new trends appear in the educational process.

The integration as a goal of education is to form students' understanding of the integrity and coherence of separate subject areas in a single structure, interrelated elements. The integration as a process of learning provides mutual interpenetration and interconnection links of the educational process branches and academic disciplines studied by students. In this process there arise changes that are evident not only in the acquisition of new links, but also in the transition of links into a different quality (formation of the professional - mathematical competence).

System core integration of mathematics and computer science in the structure of the professional-mathematical competence performs mathematical modeling.

The didactic object of mathematics and computer science integration in a holistic approach to vocational training and mathematical formation of professional - mathematical competence is the exploration and decision of professionally oriented problems of integrative nature.

\section{Results}

\subsection{Structure of the concept "professionally oriented problems of integrative nature"}

Formation of the professional-mathematical competence of students in the technical field occurs in activity by submitting a variety of tasks and problem situations. Its development is closely linked with the ability to solve professionally oriented problems of a technical nature (Kartuzova, 2010). "Solving professionally oriented problems of different difficulty levels in a specific sequence, students operate on professional terms, acquire the ability to analyze a situation typical for the future professional activities" (Dalinger, 2002). It is necessary that the student to learn how to research mathematical models of processes and phenomena as it is done in a professional activity: by applying mathematical knowledge and information technologies (Svetlov, 2011).

Under the professionally oriented problem of the integration nature we understand the problem promoting the formation of the professional and mathematical competence of students in the field of technical training, which conditions and requirements define an abstract model of a situation arising in the future professional activity of a bachelor, the problem orientating to the balance of the fundamental mathematical knowledge, practical skills and mathematical software packages usage skills (Vasiliev, 2011).

\subsection{Criteria for selection of professionally oriented problems.}

Based on the analysis of didactic approaches to the formation of educational content authors formulate criteria for the selection of professionally-oriented problems used in the framework of the professional - mathematical competence formation of students in the field of technical training through the integration of mathematics and computer science: the content of the problem must be based on a system of basic scientific knowledge, defined by the Federal State Educational Standards of Higher Vocational Education on disciplines of mathematical, science and professional cycle; in 
the context of the problem there should be included the main objects of the future professional activity of the technical graduate; integration links of mathematics and computer science and interdisciplinary links with the disciplines of professional cycle must be present in the problem; problem solving process should allow the use of mathematical software packages with its mathematical modeling and research; the link with previously studied program material, the ability to apply the knowledge gained on this topic to the problem solving must be present in the problem; the problem should be available for students of the 1-2 courses; the problem should contain elements of novelty and entertaining to motivate creativity and interest of students.

\subsection{The system of professionally oriented problems of integration nature.}

Professionally oriented problems of integration nature on mathematics and computer science are presented in three levels of difficulty (reproductive, productive, creative) and correlated with the levels of bachelors' professional and mathematical competence development (low, medium, high).

The process of research and problem solving of integration nature is a process chain which includes a number of stages correlated by authors to the steps proposed by U.M. Kolyagin (1985):

1) modeling - is a construction of a mathematical model of a real situation, the transfer of the original problem into the language of mathematical symbols and operations. At this stage students learn to analyze the problem highlighting the essential relationship between the data, determining the completeness of the initial data, describing those provisions and their relationships that are defined in the condition by mathematical symbols;

2) the study of the constructed model by methods and tools of mathematics and computer science. At this stage students learn how to choose the most appropriate method to solve this problem, to choose methods and sequence of actions, to use an auxiliary mathematical apparatus, to separate complex problems into a series of simple subtasks; to create an algorithm for solving the problem and encode it in a programming language, build a computer model using the software package;

3) interpretation is the correlation of the result with the initial situation, that is the transfer of the answer into the language of professionally oriented problems. At this stage students learn to make qualitative conclusions based on their response, to identify relevant results of this situation, to assess the meaning of the problem in the field of professional activity.

\subsection{Examples of professionally oriented problems of integration nature}

Let us consider the examples of professionally-oriented problems of integration nature "Ordinary Differential Equations" aimed at forming the professional-mathematical competence with the sequencing all stages of their research and solution.

Problem 1 (reproduction level) A condenser of $C$ capacity switches on in the circuit with voltage $U$ and resistance $R$. Determine the charge $q$ of the condenser at the time $t$ after its switching on.

Stage 1. To bring students to the construction of a mathematical model presented in the problem situation, the teacher may ask a series of leading questions to actualize the motif:

- How to submit the power $i$ of an electric current?

- What is the electromotive force acting in the circuit?

- How is formulated the Ohm's law? Is it possible to use it in this case?

After answering the questions, students receive a linear differential equation of the process:. ${ }^{R} \frac{d q}{d t}=U-\frac{q}{C}$.

Stage 2. Further, at the math lessons students solve linear equations by the known method. $q=C U-C_{1} e^{-\frac{t}{C R}}$, where $C_{1}$ - an arbitrary constant - the general solution. Using the initial conditions, we get the solution of the Cauchy problem in the way ${ }^{q=C U}\left(1-e^{-\frac{t}{c R}}\right)$.

On computer science laboratory lessons, using the Matlab package, students are looking for the numerical solution of differential equations defining the following characteristics $R=2000 \mathrm{Ohm}, C=10^{-6} \mathrm{~F}, \mathrm{U}=10 \mathrm{~V}$ (Fig. 1). 


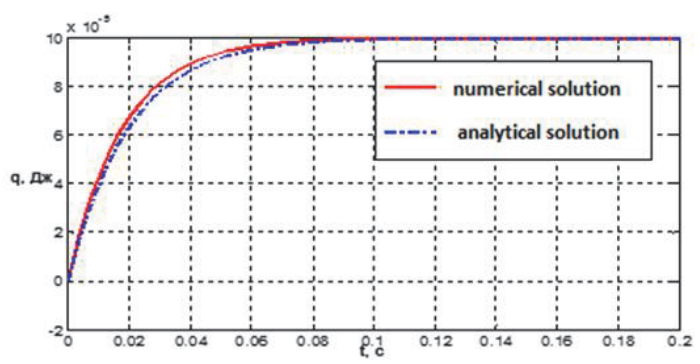

Fig. 1. Visualization of the differential equation solution

Stage 3. Students conclude that the charge on the condenser increases until it is completely saturated with a time $t=0.1$ c.

Reproductive level problems aimed at the development, acquiring and application of basic concepts, formulas, theorems. They require the ability to use known facts in a familiar situation, standard methods, both from the field of mathematics and computer science.

Problem 2 (productive level) electric current during passage through a microprocessor and other components of the electronic device generates the heat. The heat-removal heatsink, equipped with a fan, is used. Find and construct a dependency graph for a temperature $T=T(t)$ as a function of time. The airflow is automatically activated if the temperature of the microprocessor and heatsink exceeds the limit ( ${ }^{T}>T_{\max }$ ) and switches off, if ${ }^{T<T_{\min }}$ (Fig. 2). The fan's switch on is equivalent to a change of heat-exchange coefficient $\alpha$ according to the law: $\quad \alpha=\left\{\begin{array}{l}\alpha_{0}, \text { если } T \leq T_{\min } \text { или } T<T_{\max } \text { при } d T / d t>0 \\ \alpha_{1}, \text { если } T \geq T_{\max } \text { или } T>T_{\min } \text { при } d T / d t<0\end{array}\right.$, where $\alpha_{0}$ the heat-exchange coefficient with the switched off fan, ${ }^{\alpha_{1}}$ - heat-exchange coefficient at the air-flow.

Determine the section of the dependence $\mathrm{T}(\mathrm{t})$ in which the cooling system enters the operating mode $T_{\min }<T(t)<T_{\max }$. The parameters of the radiator are set by a teacher and may vary.

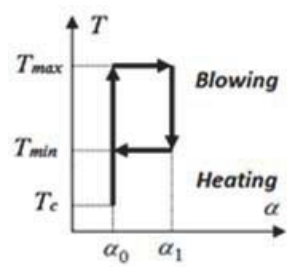

Fig. 2. Air-flow switch on and switch off

Stage 1. Formalizing the problem, the students get a mathematical model described by the differential equation $c m \frac{d T}{d t}=P-\alpha S\left(T-T_{c}\right)$, where $m$ and $c$ - mass and specific heat of the radiator's material, $T$ - radiator's temperature, $t-$ time, $P$ - released microprocessor's power, $\alpha S\left(T-T_{c}\right)$ - removed heat, $\alpha$ - convection heat-exchange coefficient, $S$ - the surface area of the radiator, $T_{c}$ - environment temperature.

Stage 2. At the math lesson students, using a known method for solving the differential equation with separable variables, determine the required formula for the temperature $T=T(t)$ as a function of $t-$ time. At the lesson on computer science using numerical methods is calculated the dependency section $T(t)$.

Stage 3. Depending on the parameters students conclude for what values $T_{\min }$ and $T_{\max }$ the system goes to the operating mode.

The problems of productive level are applied to facilitate the learning process, securing reproductive abilities and transition to a productive level. The algorithm for solving these problems is not typical, but still familiar to students. Students need to establish a link between the data in the problem and to search for the optimal solution.

Problem 3 (creative level) in a sequential circuit there are observed autonomous oscillations at the absence of an external source and charged at the time of closure of a switch $S$ of a condenser (Fig. 3). At time $t=0$, after closing the switch $S$ condenser is discharged through a circuit with a coefficient of self-inductance $L$ and resistance $R$. Find the law of voltage change $u_{c}(t)$ on the condenser plates with initial conditions $u_{c}(t=0)=U_{0}, u_{c}^{\prime}(t=0)=0$. 


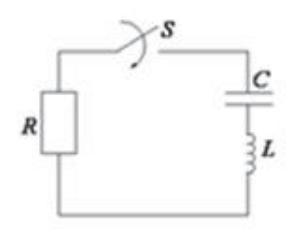

Fig. 3. Electric circuit

Stage 1. On the basis of Kirchhoff's laws the mathematical model of the problem is described by the differential equation $\frac{d^{2} u_{c}}{d t^{2}}+2 \alpha \frac{d u_{c}}{d t}+\omega_{0}^{2} u_{c}=0$, where $\alpha=\frac{R}{2 L}$ - attenuation factor, $\omega_{0}^{2}=\frac{1}{L C}$ - the natural frequency. The received differential equation is a linear homogeneous differential equation with constant coefficients.

Stage 2. Investigation of the model constructed by means of mathematics and computer science for three cases of solving of corresponding characteristic equation: $D<0, D=0, D>0$

Stage 3. Interpretation of received solutions is carried out by teachers together with students in all three cases.

Creative level problems are connected with intensification and development of knowledge. A certain intuition, thinking and creativity in the selection of mathematical tools requires for their solution. The algorithm of actions is developed by students independently.

\section{Discussions}

Intensive improvement of new technologies in many areas of engineering activity produces high demands to the future bachelors training, their professional and intellectual qualities, abilities to solve emerging challenges creatively.

Great opportunities for enhancing the formation of the professional-mathematical competence of future bachelor in the field of technical training has the interdisciplinary integration of mathematics and computer science, which involves an organic combination of objectives, a content, methods and forms of educational process organization, as well as control means of the planned result. It allows students to fully realize the professional - mathematical component of education, as well as the main directions of modern strategy of the technical education development in the context of modern society informatization.

One of the conditions of formation of the professional - mathematical competence of students in the field of technical training is the activity on solving professionally oriented problems.

Professionally oriented problems implement integrative links of mathematics and computer science, as well as interdisciplinary links with the disciplines of professional cycle; they help to shape the ability to apply mathematical concepts in solving problems of professional field; to conduct professional reading of mathematical graphs. The use of mathematical software packages allows you to display intermediate results, to plot graphs of intermediary variables, to analyze the results of the calculation when the parameters of the problem have changed, finding the most optimal solution.

\section{Conclusion}

As a result of activities on solving professionally oriented problems of the integration nature the students form their own education need in the development of generic methods and techniques of training activities; there are formed the abilities to analyze the situations, considered in problems, and to solve problems of different levels, using mathematical apparatus and information technology tools. The solution of problems contributes to the personal creative activity, shows the relationship of mathematics, computer science and special disciplines and focuses on the relationship with their chosen profession, helping to form the professional-mathematical competence.

\section{References}

Belenky, G.I., (1985) Interdisciplinary Communication. Improvement of the content of education in the school Moscow: Pedagogy, 253270.

Bezrukova, V.S. (1990). Pedagogical integration: the nature, components, mechanisms of implementation: Integration processes in educational theory and practice. Sverdlovsk.

Dalinger, V.A. (2002). Mathematical modeling as a system integration factor mathematics courses and special disciplines 
finansovo_ekonomicheskih specialties: Mathematics education in the universities of Siberia. Krasnoyarsk: CPI KSTU.

Dalinger, V.A. (2011). Computer technology in teaching geometry: method. recommendations. Omsk: OmGPU.

Federal State Educational Standard of higher education in bachelor. (2015, January 31) from: http://fgosvo.ru/fgosvpo/7/6/1

Fedoretc, G.F. (1989). The problem of integration in the theory and practice of teaching. Leningrad: RSPU.

Illarionova, G.I. Formation of professionally-mathematical competence of future engineers on safety of technological processes and production applications (PhD thesis). Available from ProQuest Dissertation \& Theses: Full Text.

Kartuzova, T.V. (2010). On the problem of the use of classroom time in the study of mathematics. Proceedings of the Scientific Conference. School Math Education: Tradition and Innovation. Ulyanovsk (p. 112-114).

Kolyagin, Y.M., \&Peak V.V. (1985). About Applied and practical orientation of teaching mathematics. Mathematics in School, 6, C 27 -32. Kulyutkin, Y.N. (1981) Modeling pedagogical systems. Moscow: Pedagogy.

Lukankin, G.L.,\& Sergeyeva G.L. (2000) Information-categorical approach to teaching mathematics younger students. Education and Informatics, 1, 81-84.

Merlin, A.V., \&Merlina, N.I.,\& Kartashova S.A. (2006). New information technologies in the teaching of higher mathematics in high school. Proceedings of the Chuvash branch of the Academy of Informatization of Education: Sat. scientific and methodological work on informatization of education. Cheboksary: Izd L.A. Naumov.

Minshin, M.M. (2011). Formation of professionally-applied mathematical competence of future engineers: the example of the training of engineers Software computer technology and automated systems (PhD thesis). Available from ProQuest Dissertation \& Theses: Full Text.

Pavlov, A.N. (2002) Integrated course of mathematics and computer science in high profile classes (PhD thesis). Available from ProQuest Dissertation \& Theses: Full Text.

Polunina, I.N. (2003). Integration of mathematics and computer science courses as a factor in optimizing the general professional training in secondary vocational schools (PhD thesis). Available from ProQuest Dissertation \& Theses: Full Text.

Solonin, V.V. (2004). Systems of computer mathematics as a means to achieve a high level of integration of physics and mathematics in personalized education. Problems of modern mathematics education in pedagogical institutes and schools of Russia: Abstracts of III All-Russian Scientific Conference. Kirov: VGGU (p.128-129).

Svetlova, N.I. (2011) Information technology in the implementation of mathematical methods in economics. Yaroslavl Pedagogical Gazette T.3, 1, 17.

Valikhanova, O.A. (2008). Formation of information-mathematical competence of students of engineering colleges in teaching mathematics using complex applications (PhD thesis). Available from ProQuest Dissertation \& Theses: Full Text.

Vasilyeva, L.N. (2011) The use of MATLAB in the course of the study of differential equations. Educational Informatics, 4. 67-73.

Vasilyeva, L.N. (2013). Formation professional mathematical competence of students using computer technology (for example, direction 210400 "Radio").Mathematics. Education: Proceedings of the 21 th Intern. Conf. (p.264) Cheboksary: Chuvashia. University Press.

Zankov, L.V. (1990). Selected pedagogical works. Moscow: Pedagogy. 